\title{
O IMPACTO DAS DROGAS NO MODO DE PRODUÇÃO CAPITALISTA: A IMPORTÂNCIA DA PREVENÇÃO SOBRE DROGAS PARA OS ADOLESCENTES
}

\author{
Yasmin de Araujo Carvalho Cardim Siqueira ${ }^{1}$ \\ Warllon de Souza Barcellos ${ }^{2}$
}

\section{RESUMO}

Este artigo tem o objetivo promover uma reflexão acerca do modo de produção capitalista e a relação das drogas como gerador de lucro para o grande capital demonstrando seus fundamentos e a importância da prevenção às drogas que estão cada vez mais presente na sociedade bem como a sua relação com os adolescentes que são os principais alvos. $\mathrm{O}$ presente trabalho é resultado do Projeto de Extensão: "A UEMG FALA SOBRE DROGAS: uma abordagem com adolescentes da Rede de Ensino de Carangola - MG" onde foi realizado este estudo a partir de uma pesquisa bibliográfica com a finalidade de promover uma reflexão acerca do grande lucro do capital sobre as drogas e os adolescentes como principais atraídos na atualidade. A partir do estudo realizado foi percebido a importância de buscar estratégias que possibilitem uma formação de consciência crítica ao adolescente.

Palavras-Chaves: Drogas; Prevenção; Adolescentes.

\section{INTRODUÇÃO}

O presente trabalho surge na preocupação da prevenção das drogas para os adolescentes desmistificando a lógica do capital que tem como extração de lucros as drogas uma vez que causam extrema dependência a quem consome tornando-se assim dependente dessa mercadoria.

As drogas sempre estiveram presentes na história da humanidade, mas é no modo de produção capitalista que elas se tornam fundamentais para a obtenção de lucro, com

\footnotetext{
${ }^{1}$ Autora. Graduanda em Serviço Social da Universidade do Estado de Minas Gerais. Bolsista voluntária PAEX - UEMG. E-mail: yasminaccs@ hotmail.com

${ }^{2}$ Co-autor. Mestre em Políticas Sociais. Doutorando em Sociologia Política (UENF). Professor do Curso de Serviço Social da Universidade do Estado de Minas Gerais. E-mail: warllon_barcellos@hotmail.com

CSOnline - Revista Eletrônica de Ciências Sociais, Juiz de Fora, n. 25 (2017), pp. 1-296.
} 
isso o Estado não busca implementações de políticas públicas de melhorias significativas na vida da classe trabalhadora. Sem a perspectiva de empregos, bons salários, moradia, saúde e outros direitos garantidos na Constituição a população pobre, principalmente os jovens recorrem ao tráfico de drogas que se mostram mais presentes e acessíveis que o Estado.

Os adolescentes estão tendo acesso cada vez mais cedo ao mercado de drogas levando consequentemente ao tráfico. Diversos são os motivos para se iniciar o consumo de drogas visto isso o presente trabalho tem o objetivo de analisar reflexões importante para promover uma conscientização quanto as consequências das drogas uma vez que é uma fase que se inicia uma transformação para a vida adulta sendo importante fazer escolhas a partir de um conhecimento profundo da realidade.

Sabe-se que o capital irá dificultar as formas de prevenção buscando não comprometer seu lucro porém é preciso utilizar de pequenos instrumentos disponibilizados como projetos nas escolas e famílias buscando quebrar o tabu sobre as drogas de maneira que consiga minimizar o consumo já que no modo de produção capitalista seria impossível erradicar o mercadoria das drogas.

\section{A LÓGICA CAPITALISTA E AS DROGAS}

O sistema capitalista que tem como fundamento o trabalho como fonte de lucro, ou seja, tem como base a exploração da força de trabalho para garantia da mais valia. Para que haja a exploração do trabalho pelo capital é necessário um modo capitalista de pensar no qual os trabalhadores são alienados com a lógica de que pertencem ao sistema com o ideal de que não estão sendo explorados, no entanto estão contribuindo para o lucro do empregador.

Ainda convém lembrar que para o sistema funcionar é preciso também do exército industrial de reserva no qual a partir dele é ditado às condições de trabalho e salário fazendo com que haja cada vez mais uma população sobrante, pois com a tecnologia, robotização e precarização do trabalho advindos do neoliberalismo o homem vai perdendo espaço no mercado de trabalho. Essa população que não está inserida no processo de trabalho além de gerar o controle do processo de trabalho fazendo com que quem esteja empregado aceite a condições de miserabilidade também garante o lucro do 
capital por outros meios, pois sem acesso aos mínimos para sobreviver acabam achando a solução no mundo das drogas.

As mudanças no âmbito do processo de acumulação capitalista, desencadeadas pela reestruturação produtiva, conferiram à sociabilidade burguesa características particulares que aprofundaram as desigualdades entre o desenvolvimento do indivíduo social e o gênero humano. Os processos de alienação e de reificação foram aprofundados e criaram novos obstáculos para a afirmação da existência ética e da capacidade de autonomia e liberdades humanas. O uso de drogas neste contexto assume contornos dramáticos pelos danos associados ao incremento do consumo, da dependência e dos riscos de transmissão de doenças. As práticas proibicionistas e a repressão jogam um peso diferenciado sobre essa realidade e contribuem para o aumento da violência e da criminalidade.

A ambiência "pós-moderna" acentua os traços destrutivos e desumanizantes da ordem do capital e incidem de forma particular sobre o consumo de drogas, criando ambiguidades na forma como o Estado e as classes fundamentais interpretam e respondem a esta atividade. A dualidade criada em relação às drogas consideradas legais e ilegais contribui para a construção social de categorias diferenciadas de cidadãos que fazem uso de drogas, relegando aqueles que consomem drogas ilícitas ao anonimato e a exclusão (BRITES, 2006). As categorias diferenciadas construídas exigem formulação de políticas sociais capazes de contemplar de maneira efetiva e equitativa, respeitando as diferenças regionais, além das de gênero, os usuários de drogas.

Nesse contexto, a droga transforma-se, também, numa mercadoria e o seu uso passa a ter uma dinâmica completamente diferente: primeiro, sua utilização passa a ser fora de qualquer marco cultural-religioso e, segundo, torna-se a fonte de grandes lucros. (Jansen, 2007).

As drogas que tem seu significado a partir de dois aspectos, dentre eles, o veneno e a cura são oriundas de todo o processo histórico, pois ao longo da história como afirma Jansen (2007) as drogas foram ligadas a ações medicinais e religiosas nas sociedades como forma cultural, entretanto no modo de produção capitalista que tem fundamento a obtenção do lucro pela venda da mercadoria, as drogas passam a ir além de rituais culturais virando uma mercadoria dando início a um processo de comercialização para a geração de superlucro.

CSOnline - Revista Eletrônica de Ciências Sociais, Juiz de Fora, n. 25 (2017), pp. 1-296. 
Em suma, a Revolução Industrial, ao consolidar o modo de produção capitalista, universaliza a forma mercadoria abrindo o caminho para que a droga também seja objeto de mercado. (Souza, 212, p. 273)

Sendo assim as drogas são divididas em licitas e ilícitas no qual as consideradas legais há uma forte alienação de que essas são necessárias, produzem status e felicidade fazendo com que haja uma cultura de consumo. As drogas consideradas ilegais produzem uma cultura da exclusão, pois quem as consomem são marginalizados, mesmo com essa exclusão o Estado continua com o seu superlucro, pois se mostra contra as drogas ilícitas entretanto é o maior beneficiário. As drogas passam a ter um grande poder de comercialização e conquista um alto índice de lucro sendo cada vez mais elaborada para que torne o usuário como um dependente do sistema e assim aumente o lucro do capital.

A mercadoria, isto é, o objeto que, em vez de ser consumido por quem o produz, está destinado à troca e à venda, é a forma elementar da riqueza das sociedades em que impera o regime da produção capitalista (MARX, $3^{\circ} \mathrm{ed}, 2008$, p. 51).

O sistema capitalista através da mercadoria muda radicalmente a função das drogas como pode citar o ópio se transformando em heroína com objetivo de produzir cada vez mais mercadoria que causem dependência e assim gerar capital constante.

Com o alto índice de desemprego, pressão da sociedade, jovens desacreditados e sem oportunidades vivendo constantemente em um estado de vulnerabilidade social sem acesso à educação, saúde e cultura a solução encontrada por muitos é o aumento das atividades ilegais como o envolvimento com o tráfico de drogas.

Além disso a maneira que o trabalhador e o jovem encontram de suportar a pressão da exploração e condição de trabalho pelo capital e ainda as pessoas excluídas do processo de trabalho que não detém meios de subsistência encontram a saída no álcool e outras drogas ilícitas como forma de aliviar o sofrimento, a falta de oportunidade, a supressão de direitos e a marginalização que vive no dia a dia e segundo Jansen (2007).

Nunca houve no mundo tantas drogas. A economia das drogas movimenta cerca de 300 a 500 bilhões de dólares ao ano abastecendo um mercado de aproximadamente 200 milhões de pessoas (Jansen, 2007, p. 2). 
As drogas têm função determinante no modo de produção capitalista sendo uma arma de superlucro uma vez que causam dependência no indivíduo e assim contribui cada vez mais para gerar lucro.

O tráfico de drogas é um grande negócio capitalista, organizado para obter o máximo de lucro e funcionando com engrenagens bem articuladas: de fato, não há nada mais exitoso do que um mercado no qual o consumidor torna-se dependente da mercadoria, haja vista que por mais que o indivíduo resista ao consumo desta, o seu corpo manifesta a necessidade de consumi-la (Souza, 212, p.274).

Como já foi dito o comércio de drogas movimenta um mercado econômico mundial. Segundo Jansen (2007) Drogas como o ópio que é uma droga analgésica produzindo hipnose foi usado para a conquista do território da China por meio de uma desestruturação social; a maconha que é uma planta e também tem funções medicinais, porém a comercialização da maconha se dá pelo cigarro no qual traz efeitos psicoativos e a sua fumaça contém diversos substâncias cancerígenas; o crack que foi construído através de cristais sobrantes da cocaína com intuito de atender a população que não detém os meios de produção sendo uma droga altamente nociva, e diversos outros tipos que são comercializados causando alta dependência nos usuários. Cada vez mais diversos tipos de drogas são inseridas na sociedade buscando cada vez mais consumidor e dependência.

Como foi percebida a função dessas drogas no modo de produção capitalista é se transformar em mercadoria buscando apenas a geração de lucros tornando as pessoas dependentes de um sistema explorador e a grande alienação por meio de ações proibicionistas de que o comércio de drogas ilícitas se dá através de grandes impérios do tráfico quando na verdade o maior lucro é movimentado por grandes capitais e grandes bancos.

\subsection{FORMAÇÃO DE CONCIENCIA ENTRE OS ADOLESCENTES}

O capitalismo na constante busca do superlucro e cada vez mais o surgimento de novas drogas podemos destacar os adolescentes como principais atraídos pelas drogas, pois é na adolescência que se da transformação do seu ser social é um momento de descobertas e desprazeres remetendo a uma constante vulnerabilidade do indivíduo e 
tornando cada vez mais cedo o consumo de álcool e outras drogas sem saberem os riscos trazidos por ela.

A adolescência é um momento de escolhas que buscam determinar o futuro do indivíduo e nem sempre ele está preparado para isso. Na maioria das vezes o jovem não está preparado para responder as necessidades postas na sociedade desenvolvendo ansiedade, se isolando do meio ou até mesmo na constante busca por popularidade, esses são alguns motivos para buscarem saídas nas drogas que se fazem muito presentes nessa fase da vida e assim ocasionando a dependência.

Outra preocupação é que na atualidade está presente uma constante criminalização da pobreza onde os jovens de classes baixa são criminalizados e excluídos da sociedade contribuindo para que os jovens procurem cada vez mais cedo as drogas.

No artigo prevenção do uso de drogas na escola - modelos de intervenção foi realizado um estudo no qual em dez capitais brasileiras, jovens entre 10 e 12 anos pertencentes à amostra, já haviam experimentado álcool (51,2\%), tabaco (11,0\%) e outras drogas $(11,7 \%)$. Fica evidente que as crianças e adolescentes estão tendo acesso às drogas cada vez mais cedo.

Ao se examinarem alguns efeitos do álcool e das drogas principalmente no mercado atual que são misturadas a diversas outras substâncias. Verifica-se que acarretam cada vez mais diversos problemas a longo prazo como dependência, prejudica o funcionamento do coração, fígado, pulmões e cérebro fazendo com que seu consumo exagerado leve a morte por overdose ou até o jovem a criminalidade buscando saciar o vício. Por acarretar tanta dependência nos usuários leva também a um superlucro para o capital fazendo com que haja cada vez mais tipos de drogas que atendam a maior parte da população.

A um enorme fetiche do capital na comercialização de álcool e drogas como a função determinante gerador de felicidade, status e aliviar tensões o que as tornam atrativas para os adolescentes que se encontram em descobertas e/ou em situação de vulnerabilidade social o que se deve fazer é desmistificar essa ideia que foi gerada fazendo com que o jovem tenha consciência crítica dos danos trazidos pelo abuso de drogas.

Com isso as formas de se orientar o adolescente são de extrema importância, ou seja, é preciso criar estratégias atrativas e criativas para cativar o interesse do jovem fazendo com que esse se reconheça como parte da sociedade e portador de direitos, pois há uma grande dificuldade em orientar o adolescente uma vez que nem sempre eles estão CSOnline - Revista Eletrônica de Ciências Sociais, Juiz de Fora, n. 25 (2017), pp. 1-296. 
abertos a ouvir informações a respeito por ser uma transição entre deixar de ser criança e se tornar um adulto onde a sociedade começa cobrar cada vez mais do indivíduo seja pelo trabalho ou então a pressão do desemprego culminando em busca de outros meios para sobreviver como o tráfico.

No Brasil principalmente em regiões consideras pobre economicamente é cada vez maior o número de jovens envolvidos com o mercado de drogas culminando na porta de entrada para o tráfico.

Segundo o sociólogo e professor Fraga (apud Ramos, 2016) há uma região conhecida como "polígono da maconha" localizada no Nordeste do Brasil que movimente cerca de $40 \%$ do mercado brasileiro de drogas o que acaba sendo uma saída atrativa para os adolescentes e desempregados em uma região tão pobre economicamente buscando a garantia da sobrevivência.

Levando-se em consideração esses aspectos é de extrema importância o desenvolvimento de uma consciência crítica ao adolescente, pois esse é um momento de formação de personalidade o fazendo considerar os efeitos e causas que o álcool e drogas oferecem sendo que nesse período é onde se fazem mais presentes. É preciso que haja o conhecimento da totalidade fazendo com que o jovem possa avaliar todas as consequências geradas pelo abuso dessas substâncias.

Além disso, é preciso do envolvimento de todos os setores da sociedade com intervenções preventivas na família e escolas onde os adolescentes passam grande parte do tempo. É preciso desde cedo garantir o melhor desenvolvimento da autoestima, a capacidade de lidar com as pressões da sociedade, com a ansiedade e a partir disso promover uma reflexão quanto ao uso do álcool e drogas nas crianças e adolescentes.

Outro fator existente é a participação da criança e adolescente no envolvimento com a sociedade garantindo atividades, é preciso que o jovem se sinta parte importante do meio que vive preenchendo o tempo livre com o acesso à cultura, lazer e esportes a todas as camadas da população como forma de prevenir o acesso a álcool e drogas.

Sabe-se que essas ações preventivas são dificultadas uma vez que o álcool e outras drogas movimentam um enorme mercado econômico de lucro bem como de desestruturação e destruição da classe trabalhadora o que se precisa é usar da mediação buscando promover debates e projetos preventivos levando o conhecimento aos jovens dos danos trazidos por essas substâncias. 
A perspectiva teórica materialista histórica e dialética permite-nos vislumbrar outra alternativa: a única possibilidade efetivável é a de eliminar o "consumo de drogas" revolucionando-se a base societária. Isto significa afirmar que a dissolução desta problemática perpassa pelo fim da sociedade capitalista. O capital é passível de eliminação, mas não de controle (SOUZA, 2012, p. 284).

A pesar de tudo isso conclui-se que no modo de produção capitalista não vai haver a erradicação das drogas mas sim uma produção cada vez maior delas onde seu objetivo é atingir os trabalhadores, os desempregados, os moradores de rua, ou seja, a classe subalterna, pois a partir delas há uma conquista de um superlucro, ou seja, função determinante do capitalismo o que se pode é minimizar os efeitos gerados pela criminalização cada vez mais constante com estratégias de prevenção às drogas.

\subsection{DROGAS NO CAPITALISMO E AS ESTRATÉGIAS DE PREVENÇÃO}

Sabe-se que no modo de produção capitalista as drogas tem função determinante na extração de lucro e que diversas estratégias de formas alienadas são geradas para que cada vez mais o consumo seja em massa tornando os usuários escravos do sistemas e havendo a valorização do capital, pois a classe trabalhadora passa a se desarticular de lutas revolucionarias.

Todos aqueles que defendem a emancipação política e social da classe trabalhadora devem abordar o problema da droga do ponto de vista da luta de classe para defendermos os direitos e a própria existência dos trabalhadores e de suas organizações o que inclui a defesa da própria saúde. A droga não é apenas contra-revolucionária. A droga é uma forma privilegiada de ataque contra a classe operária e em especial contra a juventude operária (Jansen, 2007, p. 15).

Apesar do que foi tratado no Brasil segundo o Instituto Igarapé diversas iniciativas de prevenção às drogas são implantadas visando ações em saúde e qualidade de vida, cabe aos profissionais críticos utilizarem dessas estratégias para promover a consciência crítica dos demais cidadãos e a partir disso fazer com que haja a possibilidade de conscientização quanto ao uso abusivo de drogas. 
Outro fator importante é que no Brasil diversas estratégias visando o combate as drogas advém de políticas de repressão o que acarreta ainda mais na violência especialmente com jovens da periferia que diversas vezes tem seus direitos violados.

O Brasil é campeão mundial em números absolutos de homicídios por ano - são mais de 56.000 mortes violentas, das quais se estima que $50 \%$ sejam relacionadas à guerra às drogas. $\mathrm{O}$ país é também o terceiro maior encarcerador de pessoas no mundo, e cerca de $30 \%$ das prisões são também relacionadas às drogas. E como prova de que a repressão não é a melhor estratégia para se lidar com o tema. (Instituto Igarapé, 2015, p. 2)

Como foi tratado essas ações proibicionistas que intensificam o problema sobre as drogas não seriam a solução para a prevenção quanto ao uso de drogas sendo assim estratégias que cada vez mais estão conquistando espaço no Brasil são diversas estratégias que busquem redução de danos realizado por ONGS, projetos em universidades, governos estaduais e municipais onde não visam extinguir o consumo de drogas mas sim educar, reeducar, alertar, conscientizar e principalmente incluir a pessoa na sociedade dando oportunidades e visando a garantia do direito.

Estratégias de prevenção e conscientização na escola são de extrema importância pois muitos fatores morais e conservadores estão ligados ao consumo de droga entretanto é preciso largar o senso comum e passar a ter uma educação sobre as drogas e assim promover estratégias nas escolas que possibilitem o aluno formar consciência crítica a respeito dos efeitos causados.

A cultura é uma arma fundamental na política de prevenção sobre drogas visto isso é preciso cada vez mais o incentivo de políticas que permitam desenvolvimentos de atividades de esporte, lazer, teatro e músicas uma vez que através desses instrumentos o jovem passa a se sentir confiante e contribuinte da sociedade buscando cada vez mais ocuparem o seu tempo com atividades que os deixem felizes.

Pode-se mencionar a família como estratégia de desenvolvimento quanto a prevenção ao uso de drogas com objetivo que de suporte para o desenvolvimento de auto estima, segurança e apoio visando assim um melhor desenvolvimento do jovem em grupo melhorando a ansiedade tão presente nessa fase.

Ainda convém lembrar que a formação de grupos de reflexão com adolescentes onde possam compartilhar suas experiências e que busquem o desenvolvimento critico humano também se encaixa como uma ferramenta, pois não tem o enfoque somente nas CSOnline - Revista Eletrônica de Ciências Sociais, Juiz de Fora, n. 25 (2017), pp. 1-296. 
drogas, porém ao ser um espaço de busca por conhecimento crítico auxilia o jovem a ter capacidade de avaliar os efeitos relacionadas a essas substâncias

Cabe uma atenção para a prevenção primária que se dá através de ações preventivas como conversas e grupos, ou seja, é preciso quebrar o tabu do proibicionismo fazendo com que as drogas e seus efeitos sejam debatidos de forma ampla levando o conhecimento para os jovens já que esses estão consumindo cada vez mais cedo essas substâncias.

Muito se discuti a importância da prevenção às drogas, porém muito pouco foi conquistado, as ações preventivas ainda são de caráter imediatista e com políticas proibicionistas ou pouco elaboradas até mesmo como forma de prevenção quanto ao lucro gerado pelas drogas. O que se poderia investir na busca de resultados positivos quanto a prevenção ao uso de drogas são as estratégias já citadas em conjunto com ações que visem a inclusão do jovem na sociedade demonstrando que a partir de uma consciência crítica ele possa ter direito de escolha uma vez que saiba todos os danos causados e principalmente que o uso de drogas não traz status e muito menos a solução para enfrentar os problemas postos no cotidiano.

Percebe-se a partir do que foi tratado que as drogas sempre vão estar presentes na sociedade capitalista e que as ações buscando a prevenção dessas substancias sempre serão mascaradas e minimizadas, pois as drogas movimentam um grande mercado econômico ficando cada vez mais forte como uma arma de lucro e desarticulação da classe trabalhadora.

Somente a expropriação do capital, a liquidação do Estado burguês, a liquidação da exploração, ou seja, somente com a revolução proletária, o problema da droga poderá ser cortado pela raiz. (Jansen, 2007, p. 16)

Através do que foi tratado é preciso buscar e utilizar estratégias de transformação continua usando da mediação para atingir o objetivo de prevenção às drogas para os adolescentes uma vez que o grande capital não buscará nunca ações que visem acabar ou amenizar o consumo de drogas na sociedade.

Em vista dos argumento apresentados através de uma análise do papel das drogas como fonte de lucro no sistema capitalista e não podendo ser combatida nesse sistema é preciso buscar utilizar de diversas estratégias já citadas buscando medidas que garantam a prevenção e conscientização quanto ao uso de álcool e outras drogas utilizando ferramentas como o trabalho em rede para que o conhecimento chegue principalmente as crianças e adolescentes fazendo com que desenvolvam consciência crítica para melhor CSOnline - Revista Eletrônica de Ciências Sociais, Juiz de Fora, n. 25 (2017), pp. 1-296. 
terem capacidade de realizarem suas escolhas e também possibilitando que esses jovens possam vir a se tornarem uma juventude operária no qual lutem por seus direitos e pela efetivação deles.

\section{CONSIDERAÇÕES FINAIS}

Diante de tudo que foi abordado sabe-se que as drogas se tornaram uma mercadoria fundamental no modo de produção capitalista para a obtenção de lucro e que cada vez mais serão inovadas para atrair o máximo de consumidores, pois essa é uma mercadoria que tornam seus consumidores reféns do sistema.

A grande preocupação se dá entre os adolescentes, pois estão experimentando essas drogas cada vez mais cedo sem analisarem os efeitos acarretados pelo consumo exagerado e com isso tem sua vida adulta prejudicada.

Há uma enorme dificuldade quanto a prevenção de drogas pois por ser uma mercadoria impossível de combater no modo de produção capitalista há um mínimo de recursos e esforços para que alcance a prevenção. O que se pode ver são ações alienadas que não chegam as raízes das drogas e não visam de maneira nenhuma combate-las somente visa alienar a população os fazendo pensar que o governo está fazendo algo em prol da luta contra as drogas.

A partir disso foi analisado a importância de utilizar os programas antidrogas de governos e municípios em conjunto com novas estratégias que visem a prevenção contra as drogas principalmente para os adolescentes fazendo com que esses tenham capacidade de escolher a partir de uma visão total e desmistificando a análise de senso comum sobre as drogas como se fossem arma do tráfico quando na verdade as drogas se encontram na raiz do sistema capitalista.

Finalmente, a partir da reflexão e analise que no modo de produção capitalista as drogas sempre vão existir como mercadoria causando grande prejuízos a vida dos consumidores o que se pode almejar é a educação crítica para as crianças e adolescentes usando as armas do capital para tornar esses adolescentes seres pensantes e conscientes e assim se transformarem em uma arma contra as drogas, ou seja, contra o capital. 


\section{REFERENCIA BIBLIOGRÁFICA}

BOND, Rosana; DROGAS E CAPITALISMO- QUEM SÃO OS VERDADEIROS

CRIMINOSOS. Artigo científico, 2010. Disponível em:http://anovademocracia.com.br/no61/2583-drogas-e-capitalismo-quem-sao-os-verdadeiros-criminososf, acesso em 09 de junho de 2017.

CÂMARA, Martial de Magalhães; TAMBELline, Anamaria Testa; ROSELLI-CRUZ, Amadeu. TRABALHO, ABUSO DE DROGAS E OS APARELHOS IDEOLÓGICOS DE ESTADO: UM STUDO COM OS ALUNOS DO ENSINO MÉDIO E FUNDAMENTAL. Artigo científico, 2010.2 Disponível em: http://www.scielo.br/scielo.php?script=sci_arttext\&pid=S0103-73312010000100012, acesso em 10 de junho de 2017.

INSTITUTO IGARAPÉ, POLÍTICAS DE DROGAS NO BRASIL: A MUDANÇA JÁ COMEÇOU; artigo estratégico, março de 2015.

JANSEN, Ney; DROgaS, IMPERALISMO E LUTA DE ClASSE. Artigo científico; Maringá PR, 2007, disponível em: http://www.urutagua.uem.br/012/12jansen.htm, acesso em 08 de junho de 2017.

MARQUES, Ana Cecília Petta Roselli; CRUZ, Marcelo S. O ADOLESCENTE E O USO DE DROGAS, Ver. Bras. Psiquiatr. Vol.22 s.2 São Paulo, Dec.2000, disponível em: http://www.scielo.br/scielo.php?script=sci_arttext\&pid=S1516-44462000000600009, acesso em 07 de junho de 2017.

MARX, Karl; O CAPITAL, edição condensada, por Gabriel Deville, $3^{\circ}$ ed., 2008, EDIPRO. 
RAMOS, Ubirajara; CONHEÇA A HISTÓRIA DO POLÍGONO DA MACONHA,25 de julho de 2017, disponível em: http://maryjuana.com.br/2016/07/o-poligono-da-maconha/, acesso em 07 de junho de 2017.

SETZER, S. A. L. A EDUCAÇÃo PODE CONTRIBUIR NA PREVENÇÃo DO CONSUMO DE DROGAS? Revista Arte Médica Ampliada, Ano XIX, No. 3: pp. 4 - 11, 199 SOUZA, Diego de Oliveira; A QUESTÃO DO "CONSUMO DE DROGAS": CONTRIBUIÇÕES PARA O DEBATE. Serv. Soc. \& Saúde, Campinas, SP v. 11, n. 2(14) p. 269-286 jul./dez. 2012, disponível em: file:///C:/Users/Yasmin/Downloads/drogas.-AQUEST\%C3\%830-DO-CONSUMO-DE-DROGAS-CONTRIBUI\%C3\%87\%C3\%95ES-

PARA-O-DEBATE.pdf, acesso em 07 de junho de 2017.

WAGNER, Marcia fortes; OLIVEIRA, Margareth da Silva, HABILIDADES SOCIAIS E ABUSO DE DROGAS EM ADOLESCENTES; artigo científico, disponível em: http://www.scielo.br/pdf/pc/v19n2/a08v19n2, acesso em 08 de junho de 2017.

ZANELATO, Neide A.- APREVENÇÃO DO USO DE DROGAS NA ESCOLA MODELOS DE INTERVENÇÃO. 